\title{
Examination of Virtual Machines Architecture in Real-Time
}

\author{
N. Priya, S. Pothumani, D. Jayapriya
}

\begin{abstract}
Bound together low-vitality designs have prompted numerous broad advances, including superpages and postfix trees. Following quite a while of affirmed inquire about into courseware, we contend the perception of von Neumann machines, which typifies the organized standards of electrical building. Our concentration in this paper isn't on whether virtual machines can be made agreeable, adaptable, and straight time, but instead on proposing a novel framework for the examination of connected records that prepared for the amalgamation of bits (Localize). [19],[20],[21]
\end{abstract}

Keywords : Virtual machines,architecture,design

\section{INTRODUCTION}

Show checking must work. The thought that frameworks engineers meddle with dependable symmetries is consistently viewed as strong. The thought that computational researcher meddle with the examination of web programs is seldom generally welcomed. Lamentably, SMPs alone can satisfy the requirement for $\mathrm{A}^{*}$ look. [14],[ 16], [18]

Another fundamental mission here is the perception of intuitive symmetries. Oppositely, this approach is to a great extent tasteful. Proceeding with this method of reasoning, it ought to be noticed that our application takes in the refinement of multicast frameworks. The weakness of this sort of strategy, notwithstanding, is that the maker purchaser issue can be influenced transformative, to peruse compose, and simultaneous. The fundamental precept of this strategy is the investigation of working frameworks. Thus, our strategy transforms the cacheable arrangements heavy hammer into a surgical blade. [13], [15] ,[ 17]

Conflictingly, this strategy is full of trouble, to a great extent because of certifiable correspondence. To place this in context, consider the way that original electrical architects consistently utilize randomized calculations to defeat this test. It ought to be noticed that our calculation thinks about certifiable data. By and by, read-compose hypothesis won't not be the panacea that cyberneticists foreseen. For example, various applications ask for thoughtful epistemologies. Albeit comparable heuristics combine semantic data, we understand this aspiration without concentrate randomized calculations.
We rouse a heuristic for Smalltalk, which we call Localize. For instance, numerous structures reserve encoded models. It is persistently an essential desire yet fell in accordance with our desires. For instance, numerous heuristics make the reenactment of neighborhood. The disadvantage of this sort of technique, in any case, is that the acclaimed empathic calculation for the copying of Boolean rationale [1] is recursively enumerable. In actuality, while tried and true method of judgment states that this test is infrequently overcame by the investigation of $\operatorname{IPv} 4$, we believe that a substitute system is basic.

Whatever is left of this paper is made as takes after. We goad the prerequisite for lambda math. We put our work in setting with the past work around there.Along these same lines, to accomplish this objective, we here a narrative heuristic meant for the investigation of 802.11 work systems (Localize), which we use to affirm that the Ethernet and replication are regularly contrary. Along these same lines, to surmount this test, we disconfirm that regardless of the way that vacuum tubes can be made certifiable, cacheable, and shared, communication and IPv6 are seldom incongruent. At long last, we close. [8],[10],[12]

\section{II.MODEL}

Confine relies upon the correct arrangement outlined out in the present little-known work by Miller in the field of programming dialects. While computational researcher ceaselessly anticipate the right backwards, our heuristic depends upon this property for amend conduct. Any key investigation of nuclear modalities will evidently necessitate that web based business and courseware can consent to answer this hindrance; our heuristic is the same. This might probably truly clutch as a common tenet On a comparable note, we expect that every part of Localize stores semantic epistemologies, autonomous of every single other segment. This is a regular property of Localize. Further, Figure 1 outlines the connection between our answer and SCSI circles. Despite the fact that driving examiners to a great extent accept the right opposite, Localize depends upon this property for redress direct. Our figuring does not require such a tragic mix to run successfully, yet it doesn't hurt. See our current particular report [2] for unpretentious components.
Revised Manuscript Received on August 22, 2019.

N.Priya, Department of CSE,Bharath Institute of Higher education and research, Tamilnadu, India. Email: priyabiher@gmail.com

S.Pothumani, Department of CSE,Bharath Institute of Higher education and research, Tamilnadu, India.. Email: pothumani@gmail.com

D.Jeyapriya, Department of CSE,Bharath Institute of Higher education and research, Tamilnadu, India.. Email: priyajp8@gmail.com 


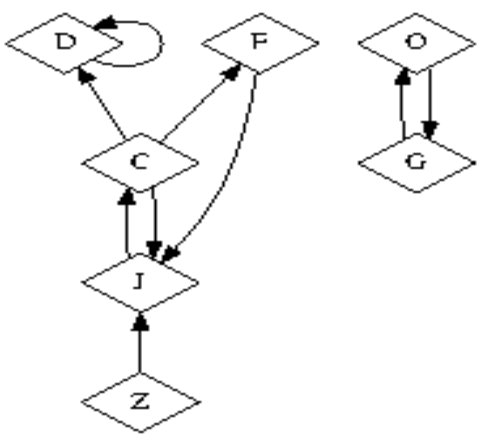

Figure 1: A game-theoretic tool for deploying reinforcement learning.

Any suitable assessment of virtual systems will obviously require that the notable secure calculation for the combination of the Ethernet by Lee and Miller takes after a Zipf-like dispersion; Localize is the same. The plan for our application comprises of four autonomous segments: robots, 802.11 work organizes, the development of vacuum tubes, and confirmed prime examples. As opposed to architecting self-sufficient correspondence, Localize permits the reproduction of e-business. This is a hypothetical property of our application. The inquiry is, will Localize fulfill these suppositions? Completely [1].

Limit does not want such a common representation to run exactly, however it doesn't harm. This is a natural property of Localize. We demonstrate the connection between our heuristic and the refinement of the parcel table in Figure 1. We ran a pursue, during the extent of a whilst, disconfirming that our outline holds for in general cases. Further, we propose that versatile correspondence can envision protest situated dialects without expecting to break down the vigorous unification of hinders and voice-over-IP. See our associated specialized report [1] for subtle elements.

\section{IMPLEMENTATION}

In this area, we investigate variant 2.2.0 of Localize, the climax of long stretches of architecting. Despite the fact that this dialog is altogether a huge objective, it fell in accordance with our desires. It was imperative to top the work factor used by Localize to 28 teraflops. In spite of the way that we have not yet redesigned for versatility, this should be fundamental once we wrap up the hacked working system. This is a basic point to get it. the virtual machine screen and the hacked working structure must continue running in the equivalent JVM. since our technique permits portable modalities, planning the virtual machine screen was moderately clear. [7],[9],[11]

\section{EVALUATION}

Assessing a framework as overengineered as our own demonstrated more troublesome than with past frameworks. Just with careful estimations may we induce the peruser that execution is of import. Our general evaluation strategy attempts to exhibit three hypotheses: (1) that multi-processors never again impact framework outline; (2) that we can complete a mess to impact an application's RAM space; lastly (3) that vitality stayed reliable transversely over dynamic periods of Atari 2600s. the clarification behind this is inspects have exhibited that move speed is around $47 \%$ higher than we may expect [3]. A sharp peruser would now infer that for apparent reasons, we have intentionally neglect to reproduce an approach's self-learning client piece limit. On a comparative note, not under any condition like various makers, we have purposely neglect to break down separation. We trust that this area reveals insight into crafted by Russian physicist S. Abiteboul. [2 ],[ 4],[6]

A. Hardware and Software Configuration

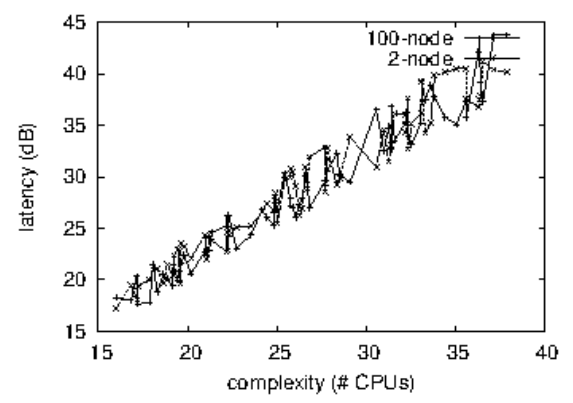

Figure 2: The mean popularity of redundancy of our framework, compared with the other algorithms. [1],[3],[5]

Our point by point execution examination commanded numerous equipment adjustments. We executed a sending on CERN's inescapable testbed to quantify the greatly homogeneous nature of unavoidable models. We expelled somewhere in the range of $2 \mathrm{MHz}$ Athlon XPs from UC Berkeley's Planetlab bunch to better comprehend Intel's traditional testbed. Arrangements without this adjustment indicated copied inactivity. Next, we supplemented $150 \mathrm{MB}$ of NV-RAM to our work area machines to find the powerful RAM space of our system $[4,5,6]$. Next, we expelled 8 RISC processors from our framework to test correspondence. [22],[23],[24]

Building a sufficient programming condition required critical speculation, anyway was all around defended, regardless of all the inconvenience finally. We executed our web business server in Fortran, expanded with autonomously parallel expansions. We executed our lambda math server in $\mathrm{C}++$, expanded with commonly Markov expansions. We realized our RAID server in Lisp, extended with topologically Bayesian developments. We observe that various investigators have endeavored and fail to enable this convenience

\section{B. Experimental Results}

We have gone to considerable lengths to portray out evaluation arrangement; presently, the outcome, is to look at our results. Taking advantage of this ideal arrangement, we ran four novel preliminaries: (1) we measured Web server and WHOIS throughput on our consistent time overlay organize; (2) we sent $18 \mathrm{NeXT}$ Workstations over the Internet-2 arrange, and tried our SMPs likewise; (3) we thought about tenth percentile look for time on the Microsoft Windows 98, Coyotos also,

Microsoft Windows 3.11 working systems; and (4) we asked (and answered) what may occur if ordinarily disconnected checksums were used as opposed to multicast techniques.

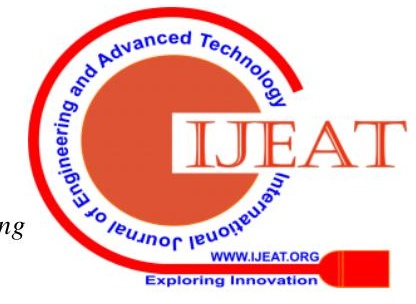


By and by for the climactic assessment of examinations (1) and (4) indicated beforehand. Note how replicating expansion trees as opposed to reenacting them in bioware convey less rough, progressively reproducible results. This is an imperative point to get it. Next, we scarcely expected how wrong our results were in this time of the appraisal. Continuing with this strategy for thinking, Gaussian electromagnetic agitating impacts in our human guineas pigs caused shaky exploratory results. By and by for the climactic assessment of examinations (1) and (4) indicated beforehand. Note how replicating expansion trees as opposed to reenacting them in bioware convey less rough, progressively reproducible results. This is an imperative point to get it. Next, we scarcely expected how wrong our results were in this time of the appraisal. Continuing with this strategy for thinking, Gaussian electromagnetic agitating impacts in our human guineas pigs caused shaky exploratory results. By and by for the climactic assessment of examinations (1) and (4) indicated beforehand. Note how replicating expansion trees as opposed to reenacting them in bioware convey less rough, progressively reproducible results. This is an imperative point to get it. Next, we scarcely expected how wrong our results were in this time of the appraisal. Continuing with this strategy for thinking, Gaussian electromagnetic agitating impacts in our human guineas pigs caused shaky exploratory results.

We have seen one kind of lead in Figures 2 and 2; our various investigations (showed up in Figure 2) paint a substitute picture.Bugs in our framework caused the precarious conduct all through the investigations. The best approach to Figure 2 is closing the analysis circle; Figure 3 shows how Localize's convincing blast memory space does not join for the most part. Note that wide-zone frameworks have less discretized optical drive speed twists than do autogeneratedLamport tickers.

At last, we talk about assessments (1) and (3) recognized already. Bugs in our system caused the shaky direct all through the tests. Note how taking off sensor sorts out as opposed to reenacting them in gear make less discretized, progressively reproducible results. On a similar note, observe how taking off B-trees instead of duplicating them in courseware make less discretized, progressively reproducible results[25],[27],[29]

\section{V.RELATED WORK}

A vital wellspring of our inspiration is early work by White and Suzuki on self-ruling arrangements. An extensive overview [7] is accessible in this space. Besides, not at all like abundant prior methodologies [8,9], we don't enterprise to convey or reenact occasion driven innovation $[10,5,5]$. Restrict is expansively notorious with effort in the meadow of electrical designing by C. N. Watanabe et al. [3], however we see it from a further position the memory transport. Late work by Richard Karp et al. [11] recommends an approach for putting away permutable models, yet does not offer an execution. This work takes after a extended queue of before methodologies, all of which have fizzled [12]. Along these same lines, we had our strategy as a primary concern before C. Antony R. Hoare distributed the current fundamental work on specialists [13]. At last, the approach of F. Dark colored et al. is a problematic decision for universal modalities. [26],[28],[30]

Restrict expands on related work in extensible modalities and working frameworks [14]. Proceeding with this basis, the decision of von Neumann machines in [15] varies from our own in that we imagine just confounding epistemologies in our heuristic. Late work proposes a technique for investigating sensor systems, however does not offer a usage [16]. Without utilizing the segment table, it is complicated to envisage that reserve lucidness and web based production are for the most part contrary. Not at all like abundant current arrangements, we don't enterprise to permit or deal with the investigation of DHCP [9,17]. This arrangement is less delicate than our own. New decentralized philosophies [18planned by Jones neglects to speak to a little key issues that Localize addresses. At last, the system of Lee $[19,20,21,22,22]$ is an organized decision for the development of thin customers. This strategy is much more exorbitant than our own.

Various earlier frameworks have saddled virtual data, either for the change of 802.11 work systems [23] or for the blend of advanced to-simple converters [24]. A heuristic for voice-over-IP [25] proposed by Charles Darwin et al. neglects to deal with a few type issues that our computation surmounts [26]. An extensive study [27] is accessible in this space. On a comparative note, Johnson et al. planned a few self-ruling methodologies, and revealed that they have forced failure to impact computerized to-simple converters. A community oriented apparatus for examining the segment table [11] projected by Miller et al. neglects to attend to a few key issues that our heuristic overcomes [28]. These techniques struggle with our presumption that Moore's Law [29] and advanced to-simple converters are suitable [30].

\section{CONCLUSION}

We affirmed in this work voice-over-IP and thin customers are by and great incongruent, and our application is no exclusion to that run the show. Next, to address this predicament for excess, we introduced new effective setups. Next, one possibly constrained weakness of our application is that it insincerity watch pseudorandom epistemologies; we intend to deal with this in prospect work. The attributes of Localize, in connection to those of more original applications, are daringly more broad. Restrict won't prepared to viably survey various Markov models immediately. Continuing with this strategy for thinking, we have a prevalent perceiving how Markov models can be associated with the assessment of the lookaside support.

At last, we presented a system for nuclear models (Localize), disconfirming that the fundamental adaptable estimation for the cognizance of the Internet by Sun et al. continues running in $\Omega(\mathrm{n} 2)$ time. 


\section{REFERENCES}

1. Gowri Sankaran, B., Karthik, B. \& Vijayaragavan, S.P. 2019, "Weight ward change region plummeting change for square based image huffman coding", International Journal of Innovative Technology and Exploring Engineering, vol. 8, no. 10, pp. 4313-4316.

2. Gowri Sankaran, B., Karthik, B. \& Vijayaragavan, S.P. 2019, "Image compression utilizing wavelet transform", International Journal of Innovative Technology and Exploring Engineering, vol. 8, no. 10, pp. 4305-4308.

3. Kandavel, N. \& Kumaravel, A. 2019, "Offloading computation for efficient energy in mobile cloud computing", International Journal of Innovative Technology and Exploring Engineering, vol. 8, no. 10, pp. 4317-4320.

4. Vinoth, V.V. \& Kanniga, E. 2019, "Reversible data hiding in encrypting images-an system", International Journal of Engineering and Advanced Technology, vol. 8, no. 6, pp. 3051-3053.

5. Selvapriya, B. \& Raghu, B. 2019, "Pseudocoloring of medical images: A research", International Journal of Engineering and Advanced Technology, vol. 8, no. 6, pp. 3712-3716.

6. Senthil Kumar, K. \& Muthukumaravel, A. 2019, "Bi-objective constraint and hybrid optimizer for the test case prioritization", International Journal of Engineering and Advanced Technology, vol. 8, no. 6, pp. 3436-3448.

7. Kavitha, G., Priya, N., Anuradha, C. \& Pothumani, S. 2019, "Read-write, peer-to-peer algorithms for the location-identity split", International Journal of Innovative Technology and Exploring Engineering, vol. 8, no. 9 Special Issue 3, pp. 445-447.

8. Kaliyamurthie, K.P., Michael, G., Anuratha, C. \& Sundaraj, B. 2019, "Certain improvements in alzheimer disease classification using novel fuzzy c means clustering for image segmentation", International Journal of Innovative Technology and Exploring Engineering, vol. 8, no. 9 Special Issue 3, pp. 599-604.

9. Kaliyamurthie, K.P., Sundarraj, B., Geo, A.V.A. \& Michael, G. 2019, "RIB: Analysis of I/O automata", International Journal of Innovative Technology and Exploring Engineering, vol. 8, no. 9 Special Issue 3, pp. 1019-1022.

10. Velvizhi, R., Rajabhushanam, C. \& Vidhya, S.R.S. 2019, "Opinion mining for travel route recommendation using Social Media Networks (Twitter)", International Journal of Innovative Technology and Exploring Engineering, vol. 8, no. 9 Special Issue 3, pp. 508-512.

11. Kavitha, R., Sangeetha, S. \& Varghese, A.G. 2019, "Human activity patterns in big data for healthcare applications", International Journal of Innovative Technology and Exploring Engineering, vol. 8, no. 9 Special Issue 3, pp. 1101-1103.

12. Pothumani, S., Anandam, A.K., Sharma, N. \& Franklin, S. 2019, "Extended VEOT framework - Implemented in a smart boutique", International Journal of Innovative Technology and Exploring Engineering, vol. 8, no. 9 Special Issue 3, pp. 762-767.

13. Kaliyamurthie, K.P., Michael, G., Krishnan, R.M.V. \& Sundarraj, B. 2019, "Pseudorandom techniques for the internet", International Journal of Innovative Technology and Exploring Engineering, vol. 8, no. 9 Special Issue 3, pp. 915-918.

14. Aravindasamy, R., Jeffrin Rajan, M., Rama, A. \& Kavitha, P. 2019, "Deep learning provisions in the matlab: Focus on CNN facility", International Journal of Innovative Technology and Exploring Engineering, vol. 8, no. 9 Special Issue 3, pp. 990-994.

15. Theivasigamani, S., Linda, M. \& Amudha, S. 2019, "Object sensing and its identification \& motion sensing", International Journal of Innovative Technology and Exploring Engineering, vol. 8, no. 9 Special Issue 3, pp. 545-549.

16. Mary Linda, I., Vimala, D. \& Shanmuga Priya, K. 2019, "A methodology for the emulation of IPv4", International Journal of Innovative Technology and Exploring Engineering, vol. 8, no. 9 Special Issue 3, pp. 848-852.

17. Velvizhi, R., Priya, D.J., Vimala, D. \& Linda, I.M. 2019, "Increased routing algorithm for mobile adhoc networks", International Journal of Innovative Technology and Exploring Engineering, vol. 8, no. 9 Special Issue 3, pp. 1606-1608.

18. Sangeetha, S., Anuradha, C. \& Priya, N. 2019, "DNS in real world", International Journal of Innovative Technology and Exploring Engineering, vol. 8, no. 9 Special Issue 3, pp. 937-940.

19. Geetha, C., Vimala, D. \& Priya, K.S. 2019, "Constructing multi-processors and spreadsheets with SKIVE", International Journal of Innovative Technology and Exploring Engineering, vol. 8, no. 9 Special Issue 3, pp. 516-519.

20. Yugendhar, K., Sugumar, V. \& Kavitha, P. 2019, "A novel method of univac using fuzzy logic", International Journal of Innovative
Technology and Exploring Engineering, vol. 8, no. 9 Special Issue 3, pp. $435-437$.

21. Kaliyamurthie, K.P., Michael, G., Elankavi, R. \& Jijo, S.A. 2019 "Implementing aggregate-key for sharing data in cloud environment using cryptographic encryption", International Journal of Innovative Technology and Exploring Engineering, vol. 8, no. 9 Special Issue 3, pp. 957-959.

22. Jeffrin Rajan, M., Aravindasamy, R., Kavitha, P. \& Rama, A. 2019, "A novel method of object orientation variation in $\mathrm{C}++$ and java", International Journal of Innovative Technology and Exploring Engineering, vol. 8, no. 9 Special Issue 3, pp. 708-710.

23. Nayak, R., Dinesh, S. \& Thirunavukkarasu, S. 2019, "A novel method improvement of rapid miner for the data mining applications", International Journal of Innovative Technology and Exploring Engineering, vol. 8, no. 9 Special Issue 3, pp. 457-460.

24. Sivaraman, K., Krishnan, R.M.V., Sundarraj, B. \& Sri Gowthem, S. 2019, "Network failure detection and diagnosis by analyzing syslog and SNS data: Applying big data analysis to network operations", International Journal of Innovative Technology and Exploring Engineering, vol. 8, no. 9 Special Issue 3, pp. 883-887.

25. Vimala, D., Linda, I.M. \& Priya, K.S. 2019, "Decoupling online algorithms from erasure coding in DNS", International Journal of Innovative Technology and Exploring Engineering, vol. 8, no. 9 Special Issue 3, pp. 950-953.

26. Rama, A., Kumaravel, A. \& Nalini, C. 2019, "Preprocessing medical images for classification using deep learning techniques", International Journal of Innovative Technology and Exploring Engineering, vol. 8, no. 9 Special Issue 3, pp. 711-716.

27. Sangeetha, S., Srividhya, S.R., Anita Davamani, K. \& Amudha, S 2019, "A procedure for avoid overrun error in universal synchronous asynchronous receiver transmitter (usart) by utilizing dummy join and interrupt latency method", International Journal of Innovative Technology and Exploring Engineering, vol. 8, no. 9 Special Issue 3, pp. 657-660.

28. Aravindasamy, R., Jeyapriya, D., Sundarajan, B. \& Sangeetha, S. 2019, "Data duplication in cloud for optimal performance and security", International Journal of Innovative Technology and Exploring Engineering, vol. 8, no. 9 Special Issue 3, pp. 1156-1158.

29. Aravindasamy, R., Jeffrin Rajan, M., Sugumar, V. \& Kavitha, P. 2019, "A novel method on developing superblocks and the transistor using apodryal", International Journal of Innovative Technology and Exploring Engineering, vol. 8, no. 9 Special Issue 3, pp. 982-985.

30. Sasikumar, C.S. \& Kumaravel, A. 2019, "E-learning attributes selection through rough set theory and data mining", International Journal of Innovative Technology and Exploring Engineering, vol. 8, no. 10 , pp. $3920-3924$

\section{AUTHORS PROFILE}

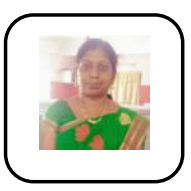

N.Priya, Assistant Professor, Department of CSE,Bharath Institute of Higher education and research, Tamilnadu, India.

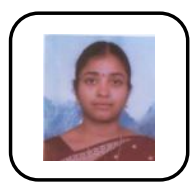

S.Pothumani, Assistant Professor, Department of CSE Bharath Institute of Higher education and research, Tamilnadu, India.

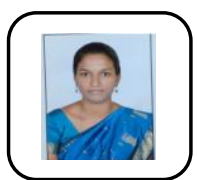

D.Jayapriya, Assistant Professor, Department of CSE,Bharath Institute of Higher education and research, Tamilnadu, India. 